\title{
Genetic diversity of Plasmodium falciparum in Grande Comore Island
}

\author{
Nasserdine Papa Mze 1,2,3,4,5*0 , Hervé Bogreau ${ }^{3,4,6,7}$, Cyrille K. Diedhiou ${ }^{1,2}$, Vendela Herdell ${ }^{8}$, Silai Rahamatou ${ }^{5}$, \\ Amy K. Bei ${ }^{1,9}$, Sarah K. Volkman ${ }^{10}$, Leonardo Basco ${ }^{3,4}$, Souleymane Mboup ${ }^{1,2}$ and Ambroise D. Ahouidi ${ }^{1,2^{*}}$
}

\begin{abstract}
Background: Despite several control interventions resulting in a considerable decrease in malaria prevalence in the Union of the Comoros, the disease remains a public health problem with high transmission in Grande Comore compared to neighbouring islands. In this country, only a few studies investigating the genetic diversity of Plasmodium falciparum have been performed so far. For this reason, this study aims to examine the genetic diversity of $P$. falciparum by studying samples collected in Grande Comore in 2012 and 2013, using merozoite surface protein 1 (msp1), merozoite surface protein 2 ( $m s p 2$ ) and single nucleotide polymorphism (SNP) genetic markers.

Methods: A total of 162 positive rapid diagnostic test (RDT) samples from Grande Comore were used to extract parasite DNA. Allelic families K1, Mad20 and RO33 of the msp1 gene as well as allelic families IC3D7 and FC37 of the msp2 gene were determined by using nested PCR. Additionally, 50 out of 151 samples were genotyped to study 24 SNPs by using high resolution melting (HRM).

Results: Two allelic families were predominant, the K1 family of msp 1 gene (55\%) and the FC27 family of msp2 gene (47.4\%). Among 50 samples genotyped for 24 SNPs, 42 (84\%) yielded interpretable results. Out of these isolates, 36 (85\%) were genetically unique and $6(15 \%)$ grouped into two clusters. The genetic diversity of $P$. falciparum calculated from msp1 and msp2 genes and SNPs was 0.82 and 0.61 , respectively.

Conclusion: In summary, a large genetic diversity of $P$. falciparum was observed in Grande Comore. This may favour persistence of malaria and might be one of the reasons for the high malaria transmission compared to neighbouring islands. Further surveillance of P. falciparum isolates, mainly through environmental management and vector control, is warranted until complete elimination is attained.
\end{abstract}

Keywords: Malaria, SNPs, msp1, msp2, Comoros

\section{Background}

Despite several interventions to prevent, control, and eliminate malaria, 219 million cases and 435,000 deaths occurred worldwide in 2018, mainly in children under 5 years and pregnant women in Africa [1]. Plasmodium falciparum remains the most dominant species in Africa and responsible for the most severe clinical forms; it is

\footnotetext{
*Correspondence: npapamze@gmail.com; aahouidi@gmail.com

${ }^{1}$ Laboratory of Bacteriology-Virology, Hospital Aristide Le Dantec, BP 7325 Dakar, Senegal

Full list of author information is available at the end of the article
}

associated with $95 \%$ of malaria-associated deaths $[2,3]$. Many factors contribute to the severity of $P$. falciparum infections, such as the level of acquired immunity of the individual and genetic characteristics of the parasite [4].

The genetic diversity of $P$. falciparum remains an obstacle to achieve malaria elimination. Previous vaccine trials have shown limited efficacy of interventions in time and different geographic regions due to genetic polymorphisms [5, 6]. The genes coding for merozoite surface protein-1 (MSP1) and merozoite surface protein-2 (MSP2) have been widely used as genetic markers to determine allelic polymorphisms

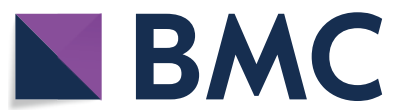

(c) The Author(s) 2020. This article is licensed under a Creative Commons Attribution 4.0 International License, which permits use, sharing, adaptation, distribution and reproduction in any medium or format, as long as you give appropriate credit to the original author(s) and the source, provide a link to the Creative Commons licence, and indicate if changes were made. The images or other third party material in this article are included in the article's Creative Commons licence, unless indicated otherwise in a credit line to the material. If material is not included in the article's Creative Commons licence and your intended use is not permitted by statutory regulation or exceeds the permitted use, you will need to obtain permission directly from the copyright holder. To view a copy of this licence, visit http://creativeco mmons.org/licenses/by/4.0/. The Creative Commons Public Domain Dedication waiver (http://creativecommons.org/publicdomain/ zero/1.0/) applies to the data made available in this article, unless otherwise stated in a credit line to the data. 
of $P$. falciparum [7-9]. The genome of $P$. falciparum is characterized by substitutions of single nucleotides occurring at specific positions in the genome, referred to as single nucleotide polymorphisms (SNPs). Approximately 112,000 SNPs have been described in the genome of $P$. falciparum and are considered useful molecular markers for barcoding to identify and characterize genetic diversity of $P$. falciparum [10-12].

In the Comoros archipelago, which is composed of four islands in the Indian Ocean between Madagascar and the African coast, malaria remains a major public health problem with high transmission and mortality rate among children under five years old [2]. Since 2004, Comoros has dramatically increased deployment of intervention strategies, including insecticide-treated bed nets, the treatment of patients with artemisinin-based combination therapy and the introduction of intermittent preventive treatment (IPT) in pregnant women. These strategies have resulted in a significant decrease in malaria infection, from 54,078 cases in 2004 to 1,072 in 2015 [13]. However, extensive interventions against malaria might as well result in changes in the population structure of Plasmodium species. First, because high genetic diversity has been associated with high levels of malaria transmission [14], a measure of genetic diversity can provide an indirect assessment of the effectiveness of an intervention [15]. Second, a high genetic structure of parasite populations, observable when gene flows between populations remain limited, allows for localized interventions. Conversely, the absence of population structure imposes the need for larger-scale strategies to be effective in the long term. Consequently, an estimation of genetic diversity in local P. falciparum isolates can provide important information on how to improve strategies to reach malaria elimination.

A 2010 study revealed a significant diversity of $P$. falciparum strains in the Union of Comoros where the mean expected heterozygosity $(\mathrm{He})$ was 0.63 in Grande Comore and the multiplicity of infection (MOI) was 1.39 from microsatellite data [16]. Since this study, only one study has been conducted to investigate genetic diversity of the parasite in Comoros [17]. The results of this latter study showed a decrease in genetic diversity and in MOI based on msp genes correlated with a decrease in malaria transmission in Grande Comore.

As a follow-up of that study, the aim of the present study was to characterize $P$. falciparum populations in other sites in Grande Comore using msp1, msp 2 and SNPs to determine the genetic diversity and MOI.

\section{Methods}

\section{Study site}

A total of 162 rapid diagnostic tests (RDTs) were collected in 2012 and 2013 in three sites of Grande Comore (Moroni $\mathrm{n}=26$, Mitsamiouli $\mathrm{n}=59$, and Mbeni $\mathrm{n}=77$ ). Malaria transmission varies in these three sites: hypoendemic in Moroni, mesoendemic in Mitsamiouli, and hyperendemic in Mbeni [16] (Fig. 1). The following RDTs were used in Grande Comore at the time of the present study: CareStart ${ }^{\mathrm{TM}}$ Malaria HRP2/pLDH Combo RDT (Access Bio, Inc., Somerset, NJ) and Standard Diagnostics Bioline Malaria Ag Pf/Pan test (SD Bioline/ Abbott, Yongin-si, Gyeonggi-do, Republic of Korea). RDTs that were positive for $P$. falciparum were collected from health centres. RDTs that were negative or invalid were excluded from this study. All RDTs were stored at room temperature until they were used for DNA extraction.

\section{DNA extraction}

Parasite DNA stored on the nitrocellulose membrane of RDTs was extracted according to the protocol developed by Cnops et al. [18]. DNA extraction was performed using QIAmp DNA or Blood Mini kit (Qiagen, Germantown, $\mathrm{MD}$ ) following the manufacturer's instructions.

\section{Genotyping of $m s p 1$ and $m s p 2$}

Msp 1 and $m s p 2$ genes were amplified by nested PCR as described in earlier studies [19, 20]. All PCR amplifications were carried out in a total volume of $20 \mu \mathrm{l}$ containing $6 \mu$ Gotaq $^{\circledR}$ DNA polymerase-reaction buffer (Promega Corporation; Madison, WI), $0.5 \mu \mathrm{M}$ of each primer, and $11 \mu \mathrm{l}$ reagent grade water. The cycling conditions for the primary PCR were as follows: initial denaturation at $95^{\circ} \mathrm{C}$ for $5 \mathrm{~min}$, followed by 35 cycles of $94{ }^{\circ} \mathrm{C}$ for $1 \mathrm{~min}, 58^{\circ} \mathrm{C}$ for $2 \mathrm{~min}, 72{ }^{\circ} \mathrm{C}$ for $2 \mathrm{~min}$, with a final extension cycle of $72{ }^{\circ} \mathrm{C}$ for $3 \mathrm{~min}$. The cycling conditions for the nested PCR were as follows: initial denaturation at $95{ }^{\circ} \mathrm{C}$ for $5 \mathrm{~min}$, followed by 35 cycles of $94{ }^{\circ} \mathrm{C}$ for $1 \mathrm{~min}$, $61{ }^{\circ} \mathrm{C}$ for $2 \mathrm{~min}, 72{ }^{\circ} \mathrm{C}$ for $2 \mathrm{~min}$, with a final extension cycle of $72{ }^{\circ} \mathrm{C}$ for $3 \mathrm{~min}$. Positive controls and negative control were run in each PCR. PCR products were analysed by gel electrophoresis on $2 \%$ agarose gels and visualized under ultraviolet trans-illumination (Biorad Gel $\mathrm{Doc}^{\mathrm{TM}} \mathrm{XR}+$ System with Image Lab). A 100 bp DNA ladder (Quick-Load) was used to determine the size of PCR products.

The expected sizes of PCR products for the $m s p 1$ gene were between $150-300 \mathrm{bp}, 130-230 \mathrm{bp}$, and 150-200 bp for $\mathrm{K} 1, \mathrm{MAD}$, and RO33, respectively. For the $m s p 2$ gene, the expected sizes were between $290-450$ bp for FC27 and between $450-700 \mathrm{bp}$ for IC3D7. 


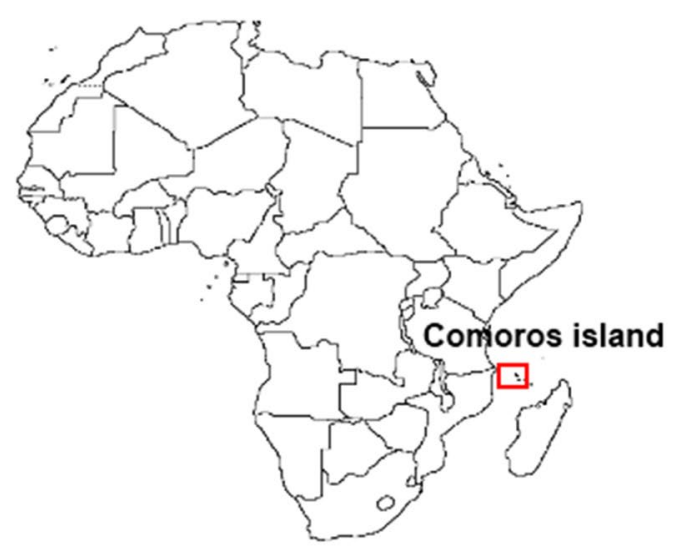

Fig. 1 Map of Grande Comore Island showing the study sites

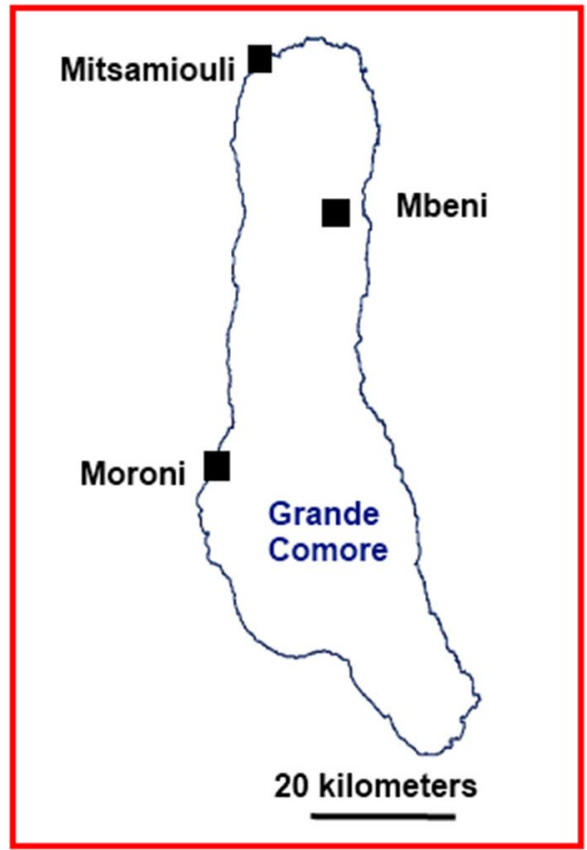

\section{Genotyping of SNPs}

Twenty-four SNPs of $P$. falciparum were genotyped by using high-resolution melting (HRM), as previously described [21]. PCR amplifications were performed using $2.5 \times$ Light Scanner master mix (Biofire Diagnostics, Inc., Salt Lake City, UT), with forward primers at a final concentration of $0.05 \mu \mathrm{M}$, reverse primers at a final concentration of $0.2 \mu \mathrm{M}$, and allele-specific probes at a final concentration of $0.2 \mu \mathrm{M}$, and $1 \mu \mathrm{l}$ of genomic DNA. SNPs were identified with a high minor allele frequency. The cycling and melting conditions for SNPs were as follows: $95^{\circ} \mathrm{C}$ denaturation for 2 min followed by 55 cycles of $95^{\circ} \mathrm{C}$ for $5 \mathrm{~s}$ and $56^{\circ} \mathrm{C}$ for $30 \mathrm{~s}$, then a pre-fusion cycle of $5 \mathrm{~s}$ each at $95^{\circ} \mathrm{C}$ and $37^{\circ} \mathrm{C}$, followed by a melt from $35^{\circ} \mathrm{C}$ to $90^{\circ} \mathrm{C}$ at $0.30^{\circ} \mathrm{C} / \mathrm{s}$.

\section{Statistical analysis}

Genetic diversity of $m s p 1$ and $m s p 2$ genes of the 3 populations (Moroni, Mitsamiouli, and Mbeni) was determined by the number of alleles per locus and by Nei [22] unbiased expected heterozygosity index $(\mathrm{He})$ using GENETIX software version 4.05 [23].

$$
H e=\left(\frac{2 n-1}{2 n}\right)\left(1-\sum_{i} x_{i}^{2}\right)
$$

where $\mathrm{n}$ is the sample size and $x_{i}$ is the frequency of ${ }_{\mathrm{i}}$ allele.

Genetic diversity index based on SNPs, equivalent to the expected heterozygosity index (He), was estimated by $\pi$ diversity index [24], implemented with MEGA X version 10.1 [25]. Phylogenetic tree, based on SNPs data, was constructed using MEGA X unweighted pair group method with arithmetic mean (UPGMA) algorithm [26].

Fisher's exact test was used to compare the allelic frequencies of $m s p 1$ and $m s p 2$ genes in three regions of the Grande Comore and He. The MOI is the mean number of fragments detected for each $m s p$ gene and each allelic family. A sample with one clone for the $m s p$ genes was considered monoclonal, while a sample with at least 2 clones was considered polyclonal. Mann-Whitney U test was used to compare mean MOI. The significance threshold was fixed at $\alpha=0.05$.

\section{Results}

Genotyping of $m s p 1$ and $m s p 2$

Of 162 samples, 151 were successfully genotyped: 25 from Moroni, 49 from Mitsamiouli, and 77 from Mbeni. Among them, 21 individual alleles were found, including 12 alleles for $m s p 1$ gene and 9 alleles for $m s p 2$ gene.

For msp1, 7 K1 type alleles (150-300 bp), 3 MAD20 type alleles (190-230 bp), and 2 RO33 type alleles (150 
and $200 \mathrm{bp}$ ) were observed (Fig. 2). The most frequent $\mathrm{K} 1$, RO33, and MAD20 type alleles were $200 \mathrm{bp}$ (60/132), 150 bp (17/18), and 200 bp (34/64) fragments, respectively. For $m s p 2$, 3 FC27 type alleles (350-450 bp) and 6 IC3D7 type alleles (450-700 bp) were obtained. For FC27, the most frequent type allele was 400 bp fragment, and the most frequent type allele for IC3D7 was $500 \mathrm{bp}$ fragment (Fig. 3).

In all three sites, the K1 family was predominant (55\%) for $m s p 1$ gene (Table 1). It was more frequent in Mbeni (71.1\%) compared to Moroni $(50 \%$; $\mathrm{p}=0.059)$ and Mitsamiouli $(30.6 \%$; $<0.01)$ (Fig. 4). There was no significant difference of $\mathrm{K} 1$ frequency between Moroni and Mitsamiouli $(\mathrm{p}>0.05)$. However, MAD20 msp1 allelic family was more frequently observed in Mitsamiouli $(22.4 \%)$ than in Moroni $(19.2 \% ; \mathrm{p}=1)$ or Mbeni $(9.6 \%$; $\mathrm{p}=0.29)$. RO33 msp1 allelic family was poorly represented (2.4-4.0\%) in all three sites.

For $m s p 2$ gene, IC3D7 allelic family was predominant in Moroni (65\%). Its frequency was lower in both Mitsamiouli (39\%; $\mathrm{p}=0.80$ ) and Mbeni (31.6\%; $\mathrm{p}=0.36$ ). The FC27 family was found to be predominant in Mbeni $(60.5 \%)$, in comparison to Moroni $(20 \%$; $\mathrm{p}<0.01)$ and Mitsamiouli (36\%; $\mathrm{p}=0.019)$.

In Moroni, a total of 10 (40\%) samples showed polyclonal infection with at least two clones, resulting in mean MOI of 1.40 (Table 2). In Mitsamiouli, 26 (53\%) samples showed polyclonal infections with at least two clones $(\mathrm{MOI}=1.57)$ and in Mbeni $26(33.8 \%)$ samples were polyclonal $(\mathrm{MOI}=1.35)$. There was no significant difference in MOI between Moroni and Mitsamiouli $(\mathrm{p}=0.30)$. In Mbeni, 26 (33.8\%) samples were polyclonal, and mean MOI was 1.35 . The difference in MOI was not statistically significant between Mbeni and Mitsamiouli $(\mathrm{p}=0.06)$ and between Moroni and Mbeni $(\mathrm{p}=0.67)$.

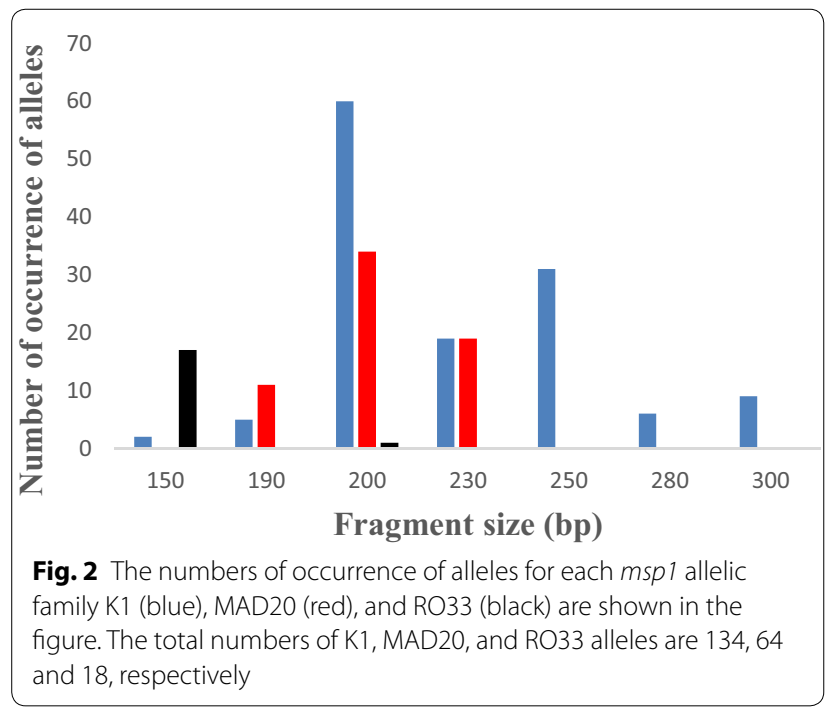

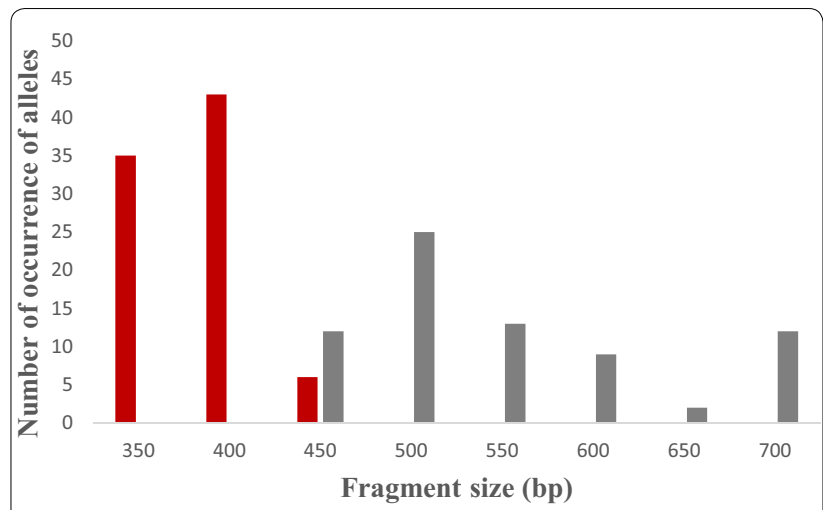

Fig. 3 The numbers of occurrence of alleles for each msp2 allelic family FC27 (red) and IC3D7 (gray) are shown in the figure. The total numbers of FC27 and IC3D7 alleles are 84 and 73, respectively

\section{Genotyping of SNPs}

In this study, 50 of 151 (33\%) samples were genotyped for 24 SNP markers. Among these, 42 samples (1 from Moroni, 17 from Mitsamiouli, and 24 from Mbeni) and 21 SNPs yielded interpretable results (Additional file 1: Table S1). These 42 samples were used for analysis by SNPs. Considering the similar level of genetic diversity included in this sub-sample $(\mathrm{He}=0.82)$ and in all 151 samples $(\mathrm{He}=0.83)$ based on $m s p$ genes, the representativeness of our sub-sample was confirmed.

Overall, 36 of 42 (85.7\%) different genotypes were obtained from 42 samples. Six of $42(14.3 \%)$ isolates grouped into two clusters, defined as a group of parasites with identical SNP barcode: one cluster consisting of $2 / 42(4.8 \%)$ parasite populations from

Table 1 Genetic diversity of $P$. falciparum msp genes in Grande Comore

\begin{tabular}{lll}
\hline Gene & Allelic family & $\mathbf{n}(\%)$ \\
\hline msp1 & K1 & $87(55.0)$ \\
& MAD20 & $24(15.2)$ \\
& RO33 & $5(3.2)$ \\
K1/MAD & $36(22.8)$ \\
K1/RO33 & $5(3.2)$ \\
MAD/RO33 & $0(0)$ \\
& K1/MAD20/RO33 & $1(0.6)$ \\
& Total K1 & $129(81.6)$ \\
& Total MAD20 & $61(38.6)$ \\
& Total RO33 & $11(7)$ \\
FC27 2 & IC3D7 & $65(47.4)$ \\
& FC27/IC3D7 & $53(38.7)$ \\
& Total FC27 & $19(13.8)$ \\
& Total IC3D7 & $84(61.3)$ \\
\end{tabular}

There was a total of $158 \mathrm{msp} 1$ and $137 \mathrm{msp} 2$ fragments 


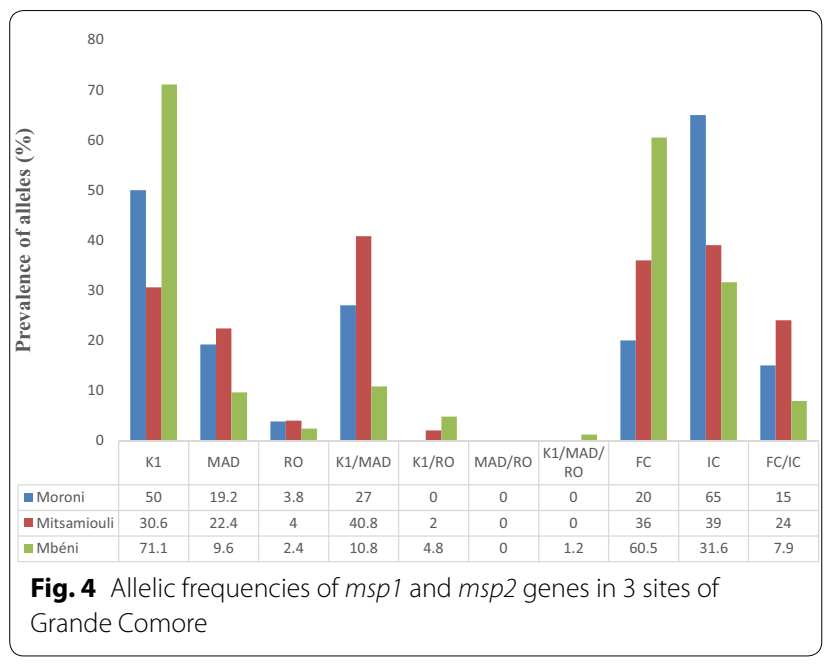

Mitsamiouli (defined by the barcode TACCXCGACXTAATAAGAXGG; " $X$ " denotes an absence of amplification) and another cluster consisting of 4/42 (9.5\%) samples from Mbeni (defined by the barcode TATTCC GTTGCCACTCGATTG). Moreover, among 36 genetically unique isolates, several had a strong linkage since they only differed from each other by a few nucleotides

Table 2 Multiplicity of infection (MOI) based on msp1 and $m s p 2$ genes in $P$. falciparum isolates from Moroni, Mitsamiouli, and Mbeni

\begin{tabular}{lllll}
\hline Sites & Moroni & Mitsamiouli & Mbeni & All sites \\
\hline msp1 & 1.46 & 1.46 & 1.29 & 1.36 \\
msp2 & 1.00 & 1.06 & 1.06 & 1.05 \\
msp1+msp2 & 1.40 & 1.57 & 1.35 & 1.43 \\
\hline
\end{tabular}

The levels of endemicity were hypoendemic in Moroni $(n=25)$, mesoendemic in Mitsamiouli $(n=49)$, meso- to hyperendemic in Mbeni $(n=77)$

(Additional file 2: Figure S1).

To investigate whether there is an association between barcode and $m s p 1$ and/or $m s p 2$ (clonality), SNPs (clusters and unique barcodes) were classified as monoclonal or polyclonal. Analysis showed that all clusters were polyclonal. Among the parasites with unique barcodes, 7 of 36 (19.4\%) were monoclonal, and 29 of $36(80.6 \%)$ were polyclonal.

\section{Allelic frequency}

Data on allelic frequency showed that several nucleotides predominated at the study sites. At P2 position, adenine (A) number predominated at all sites. At P5 position, cytosine (C) number predominated. At positions P21 and P24, adenine (A) and guanine (G) numbers were seen in the majority of isolates collected in Mitsamiouli and Moroni, respectively. The lowest minority allelic frequency (MAF) was found in position 20 in 5 of 42 (11.9\%) isolates calculated from guanine number (Additional file 1: Table S1).

\section{Genetic diversity}

Genetic diversity $(\mathrm{He})$ was estimated from $m s p$ and SNPs. For $m s p$ genes, the highest mean diversity was observed in Moroni and Mitsamiouli $(\mathrm{He}=0.84$ in both sites) (Table 3). There was no significant difference between Moroni and Mbeni $(\mathrm{p}=0.48)$. The mean genetic diversity for all sites was 0.83 (Table 3). For SNPs, He was determined at Mitsamiouli and Mbeni. The highest genetic diversity was found at Mitsamiouli $(\mathrm{He}=1)$ and the lowest at Mbeni $(\mathrm{He}=0.41)$.

In addition, He values based on $m s p$ and SNP were compared in both sites using Fisher's exact test. The He index based on $m s p$ gene was higher than the index based on SNP in Mbeni $(\mathrm{p}<0.01)$, but an opposite but insignificant trend was observed in Mitsamouili $(\mathrm{p}=0.08)$. Comparison in the whole populations did not show any difference $(\mathrm{p}=0.9)$ (Table 4).

\section{Discussion}

The Union of Comoros has entered the phase of malaria elimination after the implementation of several strategies, such as the massive use of insecticide-impregnated bed nets (ITNs), artemisinin-based combination therapy (ACT) for confirmed malaria cases, intermittent preventive treatment in pregnant women (IPTp), and mass drug administration (MDA) with artesunate-mefloquine and primaquine. However, the impact of this intervention on genetic diversity in $P$. falciparum has so far received limited attention and needs to be further investigated. In Grande Comore, genotyping of $m s p 1$ and $m s p 2$ genes revealed a high allelic polymorphism $(\mathrm{He}=0.83)$, comparable to areas of high malaria transmission in Africa [27-29]. For 12 alleles in the msp 1 gene, the K1 family was dominant (55\%). For 9 alleles in the $m s p 2$ gene, the FC27 family was most represented (47.4\%). These results are similar to those obtained in Madagascar [30] and in Grande Comore in isolates collected in 2013-2016 [17]. Interestingly, the results of the present study differ from those observed in Grande Comore in isolates collected in 2006-2007, in which RO33 family was predominant [17].

Fragment analysis of $m s p 1$ and $m s p 2$ allelic families using agarose gel electrophoresis used in the present study has limitations due to difficulties in defining specific alleles with accuracy for each isolate. To circumvent 
Table 3 Genetic diversity of $P$. falciparum at 3 sites in Grande Comore

\begin{tabular}{|c|c|c|c|c|c|c|c|c|}
\hline \multirow[t]{2}{*}{ Genetic marker } & \multicolumn{2}{|c|}{ Moroni } & \multicolumn{2}{|c|}{ Mitsamiouli } & \multicolumn{2}{|c|}{ Mbeni } & \multicolumn{2}{|c|}{ All sites } \\
\hline & $\mathbf{N}$ & $\mathrm{He}$ & $\mathrm{N}$ & $\mathrm{He}$ & $\mathrm{N}$ & $\mathrm{He}$ & $\mathrm{N}$ & $\mathrm{He}$ \\
\hline mspl & 35 & 0.86 & 74 & 0.82 & 102 & 0.81 & 211 & 0.84 \\
\hline msp2 & 31 & 0.83 & 67 & 0.85 & 101 & 0.76 & 199 & 0.84 \\
\hline$m s p 1+m s p 2$ & 66 & 0.84 & 141 & 0.84 & 203 & 0.79 & 410 & 0.83 \\
\hline
\end{tabular}

$\mathrm{He}$ is the expected heterozygosity, a measure of genetic diversity based on msp genotyping, and $\mathrm{N}$ is the number of genetically different parasite populations

Table 4 Comparison of genetic diversity using msp and SNPs

\begin{tabular}{llll}
\hline Genotyping markers & Mitsamiouli & Mbeni & Both sites \\
\hline & $\mathrm{He}(\mathrm{n}=17)$ & $\mathrm{He}^{*}(\mathrm{n}=24)$ & $\mathrm{He}(\mathrm{n}=24)$ \\
msp1+msp2 & 0.79 & 0.79 & 0.82 \\
SNPs & 1 & 0.41 & 0.61
\end{tabular}

He: heterozygosity. $\mathrm{N}$ : the number of isolates

* P-value was $<0.05$ using Fisher's exact test

this drawback, 24 SNPs were used to determine the genetic diversity of $P$. falciparum in Grande Comore for the first time. These 24 SNPs are able to identify different parasites with a high minor allelic frequency [21]. After SNP genotyping, it was found that $85 \%$ of isolates are genetically unique. These results suggest that there is a high level of genetic diversity of $P$. falciparum on the island $(\mathrm{He}=0.61)$. The results of SNP genotyping confirm those of $m s p 1$ and $m s p 2$ markers $(\mathrm{He}=0.82, \mathrm{p}=0.9)$.

The comparison of results from the studies concerning $m s p$ and barcode showed that all clusters were polyclonal. Similarly, among isolates with unique barcodes, the majority (78.9\%) were polyclonal as well although data obtained in the present study suggested that the barcode of 21 SNPs cannot predict mixed infections. MOI based on $m s p$ remains the most powerful tool for determining the number of distinct $P$. falciparum populations in an infection. The average MOI found in this study for all sites was 1.36 for $m s p 1$ and 1.05 for $m s p 2$. These results are similar to those obtained in Grande Comore in isolates collected in 2013-2016, suggesting a decreasing malaria transmission intensity on this island [17]. Moreover, the present study confirmed the decrease in genetic diversity observed by Huang et al. $(\mathrm{He}=0.95$ before intervention; $\mathrm{He}=0.84$ after intervention against malaria) [17]. However, comparison of the results of this study with those of Rebaudet et al. $(\mathrm{He}=0.63$ calculated from microsatellite markers) [16] showed discordance in the level of genetic diversity of $P$. falciparum. This may be due to the choice of $m s p$ markers used, which are biased due to immune pressure.
Moreover, the considerable level of genetic diversity was found in this study despite trends in decreased malaria transmission in Comoros. Indeed, it has been established that a high genetic diversity of $P$. falciparum is more frequent in areas of high transmission [14]. This observation may provide an explanation for malaria persistence in Grand Comore compared to neighboring islands, despite application of strategies to eliminate malaria, such as MDA. This hypothesis is supported by the fact that Grande Comore alone, compared to three other islands in the Union of Comoros, accounted for 99.4\% of malaria cases in 2014 [31]. Indeed, in Grande Comore, there are a large number of water cisterns and ablution basins which serve as mosquito breeding sites [2]. Therefore, local vector control interventions, including larval control, may be needed to improve malaria control.

\section{Conclusion}

Clinical isolates of $P$. falciparum showed high genetic diversity in Grande Comore. This might be one of the reasons for the high malaria transmission in this island, in comparison to neighbouring islands, despite the implementation of several malaria elimination strategies. Further studies on genetic diversity are essential to determine the impact of past interventions. Additionally, they may contribute to the adoption of future strategies for the achievement of malaria elimination in the Union of the Comoros.

\section{Supplementary information}

Supplementary information accompanies this paper at https://doi. org/10.1186/s12936-020-03384-5.

Additional file 1: Table S1. Molecular barcodes for sequenced P. falciparum isolates. Reference P. falciparum clones 3D7/unknown origin (airport malaria, The Netherlands), Dd2/Indochina, HB3/Honduras, and Tm90/Thailand were controls used to differentiate parasite genotypes. MAF, minority allelic frequency. $\mathrm{N}$ denotes the number of mixed alleles. $\mathrm{X}$ denotes missing nucleotide data. The frequency of minority alleles was determined by counting the number of minority allele in each position. 
Additional file 2: Figure S1. Phylogenetic tree of SNPs. Samples C13 and C34 are from Mitsamiouli and had the same nucleotide sequence. Samples C54, C48, C44, and C41 had the same sequence. They were all collected in Mbeni. Several isolates were strongly linked. For example, C22 and C24 had a single nucleotide difference. Phylogenetic tree based on SNPs data was constructed using MEGA X UPGMA algorithm.

\section{Abbreviations}

ACT: Artemisinin-based combination therapy; HRM: High-resolution melting; IPTp: Intermittent preventive treatment in pregnant women; ITNs: Insecticideimpregnated bed nets; MDA: Mass drug administration; MOI: Multiplicity of infection; msp 1: Merozoite surface protein-1; msp2: Merozoite surface protein-2; RDT: Rapid diagnostic test; SNP: Single nucleotide polymorphisms; UPGMA: Unweighted pair group method with arithmetic mean.

\section{Acknowledgements}

We thank Mohamed Abdou Said Fazul, Miradji Maamoune, and Mbaye Toyb for sample collection in Comores. We also thank Baba Dieye and Sembene Mbacke for critical reading of the manuscript and Rachel F. Daniels for analysis of results.

\section{Authors' contributions}

NPM performed experiments and wrote the manuscript. ADA and SKV conceived and designed the study. HB analysed, edited, and reviewed the manuscript. SR contributed the materials and analysis tools and offered experimental advice. CKD, AKB, and LB contributed to data analysis and reviewed the manuscript. $L B, A D A$, and SM supervised the research, wrote, read, and improved the final manuscript. All authors read and approved the final manuscript.

\section{Funding}

Not applicable.

\section{Availability of data and materials}

All data generated or analysed during this study are included in this article and are available from the corresponding author.

\section{Ethics approval and consent to participate}

Not applicable.

\section{Consent for publication}

Not applicable.

\section{Competing interests}

The authors declare that they have no competing interests.

\section{Author details}

${ }^{1}$ Laboratory of Bacteriology-Virology, Hospital Aristide Le Dantec, BP 7325 Dakar, Senegal. ${ }^{2}$ Institut de Recherche en Santé, de Surveillance Épidémiologique et de Formations, Arrondissement 4 Rue 2D1 Pôle Urbain de Diamniadio, Dakar, Senegal. ${ }^{3}$ Aix Marseille Univ, IRD, AP-HM, SSA, VITROME, Marseille, France. ${ }^{4} \mathrm{HU}$-Méditerranée Infection, Marseille, France. ${ }^{5}$ Laboratory of National Malaria Control Program, Moroni, Comoros. ${ }^{6}$ Département Microbiologie et Maladies Infectieuses, Institut de Recherche Biomédicale des Armées, Unité Parasitologie et Entomologie, Marseille, France. ${ }^{7}$ Centre National de Référence du Paludisme, Marseille, France. ${ }^{8}$ Karolinska Institutet, Berzelius väg 3, 17177 Stockholm, Sweden. ${ }^{9}$ Department of Epidemiology of Microbial Diseases, Yale School of Public Health, New Haven, CT 06510, USA. ${ }^{10}$ Broad Institute: The Broad Institute of MIT and Harvard, Cambridge, MA 02142, USA.

Received: 2 May 2020 Accepted: 15 July 2020

Published online: 03 September 2020

\section{References}

1. WHO. World Malaria Report. Geneva: World Health Organization; 2018.
2. Ouledi A. Epidemiology and control of malaria in the Federal Islamic Republic of Comoros (in French). Santé. 1995;5:368-71.

3. Papa Mze N, Ahouidi AD, Diedhiou CK, Silai R, Diallo M, Ndiaye D, et al. Distribution of Plasmodium species on the island of Grande Comore on the basis of DNA extracted from rapid diagnostic tests. Parasite. 2016;23:34.

4. Ringwald P, Peyron F, Lepers JP, Rabarison P, Rakotomalala C, Razanamparany $\mathrm{M}$, et al. Parasite virulence factors during falciparum malaria: rosetting, cytoadherence, and modulation of cytoadherence by cytokines. Infect Immun. 1993;61:5198-204.

5. Neafsey DE, Juraska M, Bedford T, Benkeser D, Valim C, Griggs A, et al. Genetic diversity and protective efficacy of the RTS, S/AS01 malaria vaccine. N Engl J Med. 2015;273:21.

6. Zeeshan M, Alam MT, Vinayak S, Bora H, Tyagi RK, Alam MS, et al. Genetic variation in the Plasmodium falciparum circumsporozoite protein in India and its relevance to RTS. S malaria vaccine PLoS One. 2012;7:8.

7. Viriyakosol SSN, Petcharapirat C, Petcharapirat P, Jarra W, Thaithong S, Brown KN, et al. Genotyping of Plasmodium falciparum isolates by the polymerase chain reaction and potential uses in epidemiological studies. Bull World Health Organ. 1995;73:85-95.

8. Conway DJ. Natural selection on polymorphic malaria antigens and the search for a vaccine. Parasitol Today. 1997;13:26-9.

9. Bouyou-Akotet MK, M'Bondoukwe NP, Mawili-Mboumba DP. Genetic polymorphism of merozoite surface protein-1 in Plasmodium falciparum isolates from patients with mild to severe malaria in Libreville. Gabon Parasite. 2015;22:12.

10. Mu J, Awadalla P, Duan J, McGee KM, Keebler J, Seydel K, et al. Genomewide variation and identification of vaccine targets in the Plasmodium falciparum genome. Nat Genet. 2007;39:126-30.

11. Jeffares DC, Pain A, Berry A, Cox AV, Stalker J, Ingle CE, et al. Genome variation and evolution of the malaria parasite Plasmodium falciparum. Nat Genet. 2007;39:120-5.

12. Volkman SK, Sabeti PC, DeCaprio D, Neafsey DE, Schaffner SF, Milner DA $\mathrm{Jr}$, et al. A genomewide map of diversity in Plasmodium falciparum. Nat Genet. 2007;39:113-9.

13. Toyb M, Ouledi A, Gaüzère BA, Aubry P. [Malaria in the Comoros Archipelago in 2015: status after 15 years of fight] (in French) Bull Soc Pathol Exot. 2016;109:107-13.

14. Anderson TJ, Haubold B, Williams JT, Estrada-Franco JG, Richardson L, Mollinedo R, et al. Microsatellite markers reveal a spectrum of population structures in the malaria parasite Plasmodium falciparum. Mol Biol Evol. 2000;17:1467-82.

15. Daniels R, Chang HH, Sene PD, Park DC, Neafsey DE, Schaffner SF, et al. Genetic surveillance detects both clonal and epidemic transmission of malaria following enhanced intervention in Senegal. PLOS ONE. 2013;8:e60780.

16. Rebaudet S, Bogreau H, Silaï R, Lepere JF, Bertaux L, Pradines B, et al. Genetic structure of Plasmodium falciparum and elimination of malaria. Comoros Archipelago Emerg Infect Dis. 2010;16:1686-94.

17. Huang $B$, Tuo F, Liang $Y, W u W, W u G$, Huang $S$, et al. Temporal changes in genetic diversity of $m s p-1, m s p-2$, and $m s p-3$ in Plasmodium falciparum isolates from Grande Comore Island after introduction of ACT. Malar J. 2018;17:83.

18. Cnops L, Boderie M, Gillet P, Van Esbroeck M, Jacobs J. Rapid diagnostic tests as a source of DNA for Plasmodium species-specific real-time PCR. Malar J. 2011;10:67.

19. Snounou G, Zhu X, Spiripoon N, Jarra W, Thaithong S, Brown KN, et al. Biased distribution of $m s p 1$ and $m s p 2$ allelic variant in Plasmodium falciparum populations in Thailand. Trans R Soc Trop Med Hyg. 1999;93:369-74.

20. Papa Mze N, Ndiaye YD, Diedhiou CK, Rahamatou S, Dieye B, Daniels $R$, et al. RDTs as a source of DNA to study Plasmodium falciparum drug resistance in isolates from Senegal and the Comoros Islands. Malar J. 2015;14:373.

21. Daniels R, Volkman K, Milner DA, Mahesh N. A general SNP-based molecular barcode for Plasmodium falciparum identification and tracking. Malar J. 2008;7:223.

22. Nei M. Estimation of average heterozygosity and genetic distance from a small number of individuals. Genetics. 1978;89:583-90.

23. Belkhir K, Borsa P, Chikhi L, Raufaste L, Bonhomme F. GENETIX 4.05, Windows software for population genetics (author's translation). Montpellier, 
France: Laboratoire Génome, Populations, Interactions, CNRS UMR 5000, Université de Montpellier II; 1996-2004. http://www.genetix.univ-montp 2.fr/genetix/genetix.htm. Accessed 27 Jun 2020 (in French).

24. Nei M, Li WH. Mathematical model for studying genetic variation in terms of restriction endonucleases. Proc Natl Acad Sci USA. 1979;10:5269-73.

25. Kumar S, Stecher G, Li M, Knyaz C, Tamura K. MEGA X: Molecular evolutionary genetics analysis across computing platforms. Mol Biol Evol. 2018;35:1547-9.

26. Sokal RR, Michener CD. A statistical method for evaluating systematic relationships. Univ Kans Sci Bull. 1958;38:1409-38.

27. Funwei RI, Thomas BN, Falade CO, Ojurongbe O. Extensive diversity in the allelic frequency of Plasmodium falciparum merozoite surface proteins and glutamate-rich protein in rural and urban settings of southwestern Nigeria. Malar J. 2018;17:1.

28. Mohammed H, Kassa M, Mekete K, Assefa A, Taye G, Commons RJ. Genetic diversity of the $m s p-1, m s p-2$, and glurp genes of Plasmodium falciparum isolates in Northwest Ethiopia. Malar J. 2018;17:1.
29. Singana BP, Mayengue PI, Niama RF, Ndounga M. Genetic diversity of Plasmodium falciparum infection among children with uncomplicated malaria living in Pointe-Noire, Republic of Congo. Pan Afr Med J. 2019;32:183.

30. Sallenave-Sales S, Daubersies P, Mercereau-Puijalon O, Rahimalala L, Contamin H, Druilhe $\mathrm{P}$, et al. Plasmodium falciparum: a comparative analysis of the genetic diversity in malaria-mesoendemic areas of Brazil and Madagascar. Parasitol Res. 2000;86:692-8.

31. Programme National de Lutte contre le Paludisme (PNLP) aux Comores. Rapport 2014, p. 5.

\section{Publisher's Note}

Springer Nature remains neutral with regard to jurisdictional claims in published maps and institutional affiliations.
Ready to submit your research? Choose BMC and benefit from:

- fast, convenient online submission

- thorough peer review by experienced researchers in your field

- rapid publication on acceptance

- support for research data, including large and complex data types

- gold Open Access which fosters wider collaboration and increased citations

- maximum visibility for your research: over $100 \mathrm{M}$ website views per year

At BMC, research is always in progress.

Learn more biomedcentral.com/submissions 